\title{
Children's use of category-size information for the retrieval of information
}

\author{
CARLA J. SPRINGER \\ University of Rochester, Rochester, New York 14627
}

\begin{abstract}
Both the accuracy of category-size information and its use during the retrieval of categorized materials were investigated among kindergarten and third-grade children as a function of degree of learning. Subjects receiving either one or three trials recalled items under one of three instructions: They were provided the size of the category, they were asked to estimate the size of each category, or they were given standard free recall instruction. Analysis of both the amount recalled and intercategory pause times indicated that children possess some category-size information before they spontaneously use it to guide retrieval. Also, categorysize information seemed to be acquired earlier in the learning situation by third-graders than by kindergartners. Results were discussed in terms of the nonexhaustive retrieval searches typically reported for young children.
\end{abstract}

Recent research efforts aimed at determining the reasons for age-related changes in recall ability (e.g., Emmerich \& Ackerman, 1978; Kobasigawa, 1977; Keniston \& Flavell, Note 1) have revealed that agerelated improvements in recall ability may be due to increased proficiency in retrieving information that has been successfully stored, as well as to differences at the time of acquisition. Such increased retrieval proficiency may well reflect important age-related differences in search and/or decision processes, such as evaluating the acceptability of information that has been recovered during a memory search, deliberately retrieving nontarget items as supplemental retrieval cues, changing search strategies, and/or terminating a memory search.

Kobasigawa (1974) has reported important agerelated differences in both the extent and manner of children's spontaneous use of external cues for retrieval, and Posnansky (1978a) has questioned whether the nonexhaustive category searches of young children were due to their using inaccurate category-size information, their failing to use available size information as the basis for search termination decisions, or to their failing to extract category-size information at all. Posnansky's results indicated that third-graders' use of categorysize information was spontaneous, while kindergartners made use of such information only when it was provided or they were explicitly required to estimate it. Furthermore, although kindergartners were able to use experimenter-provided or self-generated category-size information to make search termination decisions when

The author has formerly published under the name of Carla Posnansky. The author appreciates the assistance of Lynne Rosenzweig in collecting the data. Appreciation is also expressed to Sister Mary Dorothy Burnett and the faculty of St. Thomas More for their cooperation. Requests for reprints should be sent to the author, Center for Development, Learning, and Instruction, Lattimore Hall, University of Rochester, Rochester, New York 14627. they were required to do so, their estimations of category size were much more in error than third-graders' estimates.

The present study was designed to extend previous work on the importance of category-size information during retrieval, since such information about the size of the target set may be reasonably postulated to be the basis for each of the search processes previously described. For example, underestimating the size of the to-beretrieved set might, of course, lead to either a less than exhaustive search or a failure to change a noneffective strategy to another available search strategy. Specifically, the present experiment was designed to determine whether category-size information (information about the size of a potential recall target set) is a part of the initial information learned with items or is secondary, complementary information that is acquired at a later stage of learning. Toward this purpose, the degree of learning before size estimations and recall was varied in this study. The extent to which size information is initially rather than later acquired information and the extent to which this varies as a function of age, possibly contributing to the enhanced retrieval abilities and greater and more spontaneous use of retrieval strategies of older children, was also investigated here. Importantly, the present study also investigated whether information such as category-size information that proves useful for successful retrieval is acquired and available for use in a particular task before a retrieval strategy based on that information is used spontaneously. Thus, in the present study, the accuracy of size estimates was evaluated independently of the use of such information during recall in order to determine if children possess such information before using it spontaneously, without instruction.

\section{METHOD}

Thirty kindergarten (15 male, 15 female) and 30 third- 
grade (14 male, 16 female) children with mean ages of 5 years 10 months and 8 years 9 months, respectively, participated. Thirty-four line drawings were taken from Elwell, Murray, and Kucia (1970). The drawings were instances of eight semantic categories from the children's category norms (Posnansky, $1978 \mathrm{~b})$. The number of items per category ranged from two to seven, and there were two three- and two four-item categories. The line drawings were mounted on cards with magnetic backs. Two different list versions of randomly paired categories and category sizes were prepared so that a particular category did not represent the same category size for all subjects.

Eight cue cards were also prepared. Each was much larger than the item cards and each was a cue to one category. A tool box was the picture cue for the category "tools," for example. Each of the cue pictures was mounted on a card with a magnetized surface.

The design of the present study was a 2 (grade level) by 2 (one acquisition trial vs. three acquisition trials) by 3 (informed vs. estimation vs. standard instructions) factorial with half of the subjects in each grade level by instruction cell studying each list version.

Following the basic procedure of Posnansky (1978a), subjects were tested individually, and each began the session by casually interacting with the experimenter and practicing the experimental task with a list composed of two small categories. List presentation was designed to maximize categorical storage across ages. A cue card was placed on a stand in front of the child, and the experimenter explained that the task was to remember the little pictures that went with each cue. The category instances were then presented at approximately a 3-sec rate by attaching the magnet on the back of the category instance to the magnetized surface of the category cue. Cards were placed anywhere on the border of the cue card, and no particular number of slots or positions for category instances was obvious. After all the items for a particular cue had been presented, the next cue was placed in front of the child and the procedure was repeated. After the entire list was presented, it was repeated twice with the cues and items presented in a different random order for subjects in the three-acquisitiontrials group.

Following the two presentation trials, both the categorysize-informed and the category-size-estimate groups were shown the category cues again. In the informed group, each cue was presented, and the experimenter told the child that she would place one small, blank, magnetized card on the cue card for each of the items that went with that cue.

In the estimate group, the experimenter explained to the child that each of the items in the list could be symbolized by a blank card and that the blank cards could be placed on the cue cards in order to indicate how many items had been presented with a particular cue. Following practice in this instruction and after a large supply of blank cards was provided, the cues were presented one at a time and the child placed as many blank squares on the cue cards as he/she deemed appropriate.

In the third, standard instruction group, subjects played a block-stacking game for an amount of time that matched the time taken for category estimation by another child within the same grade by number of trials condition cell.

Oral recall of list items was then requested. For subjects in the standard group, all eight cue cards were stacked in front of the subject, who was informed that they could be handled and/or used if desired. For the remaining subjects, all cue cards remained in full view on easels with their size-indicator cards. Recall was tape-recorded.

\section{RESULTS}

In order to evaluate the effects of category-size information on retrieval strategies like those described in the introduction (e.g., deciding to abandon the search of a category), several dependent measures from the present data were analyzed, and the results of these analyses are reported separately. All results reported are significant at $\mathrm{p}<.05$.

A 2 (grade) by 2 (one acquisition trial vs. three acquisition trials) analysis of variance performed on the absolute size of estimation errors (i.e., the absolute value of the difference between estimated and actual size) revealed a highly significant effect of grade such that kindergartners' estimates were an average 6.7 items in error, while the third-graders' estimates were an average 2.4 items in error $[\mathrm{F}(1,16)=56.89]$ (see Table 1).

The effect of the number of acquisition trials was also significant $[F(1,16)=67.97]$, revealing that estimates were considerably more accurate with a greater degree of learning (mean of three trials $=2.2$ items in error; mean of one trial $=6.9$ ). The interaction of the two variables was marginally significant $[F(1,16)=3.72$, $\mathrm{p}<.06$ ] indicating a larger trial effect for kindergartners and almost errorless estimates by third-graders after three acquisition trials.

A 2 (grade) by 2 (one acquisition trial vs. three acquisition trials) by 3 (informed vs. estimate vs. standard instructions) analysis of variance was performed on the number of items recalled. Subjects receiving three acquisition trials recalled significantly more items than did subjects receiving only one trial $[F(1,48)=35.98]$ (see Table 1). Also, kindergartners recalled significantly fewer items than did third-graders $[F(1,48)=56.44]$. The interaction of Grade by Number of Trials did not reach significance, although the three-way interaction of the variables did reach significance $[\mathrm{F}(1,48)=4.75]$. Post hoc comparisons here indicated that, with one acquisition trial, there were no differences among instruction conditions for kindergartners, while less was recalled under standard, control conditions by third-graders than under either size-informed or sizeestimate conditions. With three acquisition trials, both grades showed the same superiority of size-informed over size-estimate over standard recall instructions.

The mean numbers of categories from which items were recalled are seen in Table 1 . There were no significant differences among these means.

The intervals between the last word produced in a given category and the first word produced in the next category were recorded off the recall tapes to the nearest second. These pause times were taken as an indication of continuing search of the category in question. Since category cues were readily available to all children, it was assumed that category access to a succeeding category was not a major problem. (The data bore out this assumption, since the mean number of categories from which items were recalled was 7.5.) These interval lengths and the percentage of the particular category recalled served as the two variables in a correlational analysis for each subject. Furthermore, for subjects in the estimation condition, two different 
Table 1

Summary of Mean Values for Three Dependent Measures

\begin{tabular}{|c|c|c|c|c|c|c|c|}
\hline & \multicolumn{6}{|c|}{ Instruction Condition } & \multirow[b]{4}{*}{ Mean } \\
\hline & \multicolumn{4}{|c|}{ Category Size } & \multirow{2}{*}{\multicolumn{2}{|c|}{$\begin{array}{c}\begin{array}{c}\text { Standard Free } \\
\text { Recall }\end{array} \\
\end{array}$}} & \\
\hline & \multicolumn{2}{|c|}{ Informed } & \multicolumn{2}{|c|}{ Estimate } & & & \\
\hline & Mean & $\mathbf{r}$ & Mean & $\mathrm{r}$ & Mean & $\mathrm{r}$ & \\
\hline & \multicolumn{7}{|c|}{ Kindergarten: One Acquisition Trial } \\
\hline $\begin{array}{l}\text { Number of Items Recalled } \\
\text { Number of Categories Recalled } \\
\text { Absolute Size Estimate Errors } \\
\text { Size of Underestimates }\end{array}$ & $\begin{array}{r}17.0 \\
7.2\end{array}$ & $-.22 *$ & $\begin{array}{r}18.4 \\
7.6 \\
9.6 \\
9.6\end{array}$ & $\begin{array}{l}-.22 \\
-.25 * *\end{array}$ & $\begin{array}{r}17.4 \\
7.4\end{array}$ & -.20 & $\begin{array}{r}17.6 \\
6.7\end{array}$ \\
\hline $\begin{array}{l}\text { Number of Items Recalled } \\
\text { Number of Categories Recalled } \\
\text { Absolute Size Estimate Errors } \\
\text { Size of Underestimates }\end{array}$ & $\begin{array}{r}24.4 \\
7.6\end{array}$ & -.72 & $\begin{array}{r}\text { ndergar } \\
22.4 \\
7.6 \\
3.8 \\
4.6\end{array}$ & $\begin{array}{c}\text { hree Ac } \\
-.33 \\
-.66\end{array}$ & $\begin{array}{r}\text { ion Tri } \\
20.0 \\
7.2\end{array}$ & -.36 & $\begin{array}{r}22.3 \\
7.5\end{array}$ \\
\hline $\begin{array}{l}\text { Number of Items Recalled } \\
\text { Number of Categories Recalled } \\
\text { Absolute Size Estimate Errors } \\
\text { Size of Underestimates }\end{array}$ & $\begin{array}{r}22.2 \\
7.8\end{array}$ & -.58 & $\begin{array}{c}\text { Grade } \\
22.1 \\
7.8 \\
4.2 \\
5.0\end{array}$ & $\begin{array}{c}\text { e Acqui } \\
-.35 \\
-.73\end{array}$ & $\begin{array}{r}\text { Trial } \\
17.2 \\
6.4\end{array}$ & -.22 & $\begin{array}{r}20.5 \\
7.3\end{array}$ \\
\hline \multirow[t]{2}{*}{$\begin{array}{l}\text { Number of Items Recalled } \\
\text { Number of Categories Recalled } \\
\text { Absolute Size Estimate Errors } \\
\text { Size of Underestimates }\end{array}$} & $\begin{array}{r}27.8 \\
8.0\end{array}$ & -.74 & $\begin{array}{r}\text { Grade } \\
26.8 \\
8.0 \\
.6 \\
.6\end{array}$ & $\begin{array}{l}\text { ee Acqui } \\
-.71 \\
+\end{array}$ & $\begin{array}{c}\text { Trials } \\
24.3 \\
7.2\end{array}$ & -.56 & $\begin{array}{r}26.3 \\
7.7\end{array}$ \\
\hline & & & & Mean & & & \\
\hline $\begin{array}{l}\text { Number of Items Recalled } \\
\text { Number of Categories Recalled }\end{array}$ & $\begin{array}{r}22.9 \\
7.7\end{array}$ & & $\begin{array}{r}22.4 \\
7.8\end{array}$ & & $\begin{array}{r}19.7 \\
7.1\end{array}$ & & \\
\hline
\end{tabular}

*The mean correlation coefficient of (1) the interval between the last word recalled from one category and the first word recalled from the next category (to the nearest second) and (2) the percentage of the category recalled. **The mean correlation coefficient of (1) the interval between the last word recalled from one category and the first word recalled from the next category and (2) the percentage of the category recalled when the percentage recalled is based on the size of the category estimated by the subject. tBecause of the almost errorless category-size estimates by these subjects, the correlation coefficient is based on the same data as those of real category size and pause time.

indications of the amount of a category recalled were entered into separate correlational analyses: the percentage of the actual number of items in the category and the percentage of the estimated number of items in the category. Results (means) of these correlational analyses are found in Table 1 . With one acquisition trial, kindergartners' intercategory pauses were not correlated with the proportion of the category recalled under any instruction condition, while third-graders' intercategory pause times were correlated with the extent to which a category was completely recalled under informed conditions and the extent to which subjects estimated that a category was completely recalled under estimate conditions.

With three acquisition trials, the pattern of kindergartners' correlation coefficients for pause time and the percentage of the category recalled strongly resembled the third-graders' pattern with just one acquisition trial. Thus, pause times were negatively correlated with the amount of the category recalled under both informed conditions and the estimation conditions using estimated category size. When given three acquisi- tion trials, the third-graders' pause times were negatively related to the percentage recalled under all conditions, and, additionally, the accuracy of their size estimates was so high that the two correlations within the estimation condition were based upon essentially the same data.

\section{DISCUSSION}

The findings here in terms of (1) size-estimates and (2) correlation coefficients between categories indicated that both kindergarten and third-grade children can extract and use category-size information during retrieval of a list of items. However, it appears that children possess some category-size information before they use the information to guide retrieval by continuing to search within a category that has not been completely recalled. This conclusion is based, in part, upon a comparison of kindergartners in the informed or estimate groups with the kindergartners in the standard group. While after one trial there are no differences among the kindergarten groups, subjects in the two experimental groups recalled more than did the subjects in the standard group after three trials. In addition, after three trials, there was also a negative relationship between the amount of intercategory pause time and the actual or estimated amount of a category recalled in these two groups, but not in the standard group. Importantly, though, the size estimates of kindergartners did improve with a greater degree 
of learning, so that size information was apparently obtained before it was used to guide retrieval without attention explicitly directed to it (i.e., in the standard group).

Category-size information does, however, seem to be acquired earlier in the learning situation by the third-graders than by the kindergartners. After just the initial presentation trial, thirdgraders' estimates of the number of items associated with the various recall cues were off only about $12 \%$ (almost invariably underestimates). However, once again, children did not appear to use size information spontaneously during retrieval, as seen by the low correlation between the standard subjects' intercategory pause times and the percentage of a category recalled. Later in learning, information was both amazingly accurate and utilized during retrieval even by subjects in the standard group.

It thus appears that the size of the target set or retrieval domain is a factor that older children can use to guide retrieval even at a beginning learning stage, although they do not do so spontaneously, while younger children perform similarly at a later stage of learning.

Finally, the accuracy of estimates improves over trials for children of both ages and, thus, presumably becomes a better and better basis for search decisions during retrieval. Thus, previous results, which suggest kindergartners' failure to use systematic and exhaustive retrieval strategies (e.g., Kobasigawa, 1974; Keniston \& Flavell, Note 1) may be due to the fact that these children's initial large underestimates of the size of the target domain do not prompt them to use such retrieval strategies.

\section{REFERENCE NOTE}

1. Keniston, A., \& Flavell, J. H. The nature and development of intelligent retrieval. Unpublished paper, Stanford University, 1978.

\section{REFERENCES}

Elwell, C., Murray, R., \& Kucia, M. Phonics workbook series. Cleveland, Ohio: Modern Curriculum Press, 1970

Emmerich, H. J., \& Ackerman, B. P. Developmental differences in recall: Encoding or retrieval. Journal of Experimental Child Psychology, 1978, 25, 514-525.

KoB ASIG AWA, A. Utilization of retrieval cues by children in recall. Child Development, 1974, 45, 127-134.

Kobasigawa, A. Retrieval strategies in the development of memory. In R. V. Kail, Jr., \& J. W. Hagen (Eds.), Perspectives on the development of memory and cognition. Hillsdale, N.J: Erlbaum, 1977.

Posnansky, C. J. Age- and task-related differences in the use of category-size information for the retrieval of categorized items. Journal of Experimental Child Psychology, 1978, 26, 373-382. (a)

Posnansky, C. J. Category norms for verbal items in 25 categories for children in Grades 2-6. Behavior Research Methods \& Instrumentation, 1978, 10, 819-832. (b)

(Received for publication September 21, 1979.) 